\title{
Presos políticos y presos Conintes: las investigaciones en la Cámara de Diputados de la Nación durante el frondicismo (1958-1962)
}

\author{
Sabrina Castronuovo \\ Universidad Nacional de La Plat, Argentina \\ s.castronuovolp@gmail.com
}

Cita sugerida: Castronuovo, S. (2018). Presos políticos y presos Conintes: las investigaciones en la Cámara de Diputados de la Nación durante el frondicismo (1958-1962). Anuario del Instituto de Historia Argentina, 18(2), e077. https://doi.org/10.24215/2314257Xe077 


\title{
Presos políticos y presos Conintes: las investigaciones en la Cámara de Diputados de la Nación durante el frondicismo (1958-1962)
}

\author{
Political prisoners and conintes prisoners: the investigations in the Chamber of Deputies during Frondizi's \\ government (1958-1962) \\ Sabrina Castronuovo \\ Universidad Nacional de La Plat, Argentina \\ s.castronuovolp@gmail.com
}

\section{Resumen:}

El objetivo de este trabajo es analizar el rol que ocuparon las instituciones y lugares de encierro en la persecución y detención de la disidencia política durante el frondicismo. Partimos de la premisa de que las cárceles constituyeron un factor central del engranaje por medio del cual el gobierno lidiaba con la oposición e intentaba controlarla. En la utilización diferencial de distintas unidades carcelarias según el tipo de detenido político, en las formas de detención y los circuitos de traslado constantes de muchos presos, en la aplicación de torturas, se puede advertir el rol central que ocuparon las instituciones de encierro.

Palabras clave: Frondizi, Cárcel, Presos políticos, Conintes, Cámara de Diputados.

\section{Abstract:}

The aim of this article is to analyse the role of institutions and other places of confinement in the context of political persecution and detention during Frondizi's presidency. Prisons were a central tool to deal with political opposition and to control it. Through the differential use penal institutions according to the type of political prisoner, the different procedures for detention and the circuits of constant transfer of detainees, the use of torture, we infer the fundamental role that penal institutions and other places of confinement occupied.

KEYWORDS: Frondizi, Prison, Political prisoners, Conintes, Chamber of Deputies.

\section{INTRODUCCIÓN}

El presente trabajo se propone contribuir al estudio de las prisiones y otros lugares de detención en los contextos de represión política. En particular, esta pesquisa se concentra en el período de la presidencia de Arturo Frondizi y analiza el rol que ocuparon las instituciones y lugares de encierro en la persecución y detención de la disidencia política. Estudios sobre el período aquí analizado han revelado que, a través de la promulgación de decretos y leyes, en esta etapa se habilitó por primera vez la incorporación de las fuerzas armadas como herramienta utilizada en el ámbito de la seguridad interna con el objetivo de combatir la "subversión"(Pontoriero, 2015). ${ }^{1}$ Esto fue posible a partir de la introducción en el corpus jurídico argentino relacionado a la defensa nacional de la figura de un supuesto "enemigo interno", subversivo. El despliegue de un conjunto de medidas de excepción que atentaban contra el Estado de derecho y las garantías constitucionales permitió un alto grado de represión política donde las fuerzas armadas asumieron un papel protagónico, avalado por las nuevas leyes y decretos presidenciales (Franco, 2012; Franco \& Iglesias, 2015).

A partir de estos primeros estudios y de las fuentes documentales analizadas, esta pesquisa postula la existencia de dos tipos de presos políticos durante el frondicismo. Por un lado, los perseguidos y encarcelados a través del Plan Conintes (Conmoción Interna del Estado), calificados como "enemigos internos", donde las fuerzas armadas quedaron a cargo de su persecución a través de medidas legislativas que resumiremos en el próximo apartado. Por otro lado, los detenidos a disposición del Poder Ejecutivo Nacional también por motivos políticos y gremiales, aunque no caracterizados directamente como subversivos. En estos últimos, 
las detenciones estuvieron a cargo de las policías provinciales y Federal. Planteamos entonces que puede ser posible analizar estos dos tipos de persecución política como un todo en el cual se pueden encontrar nuevos sentidos a la lógica de represión en tiempos de Frondizi. El corpus documental analizado nos permite abrir una ventana desde la óptica de las cárceles y de los procesos de detención, llevados a cabo tanto por autoridades policiales como militares, desde la cual pretendemos aportar algunas nuevas reflexiones al campo de estudios que ha comenzado a abrirse en los últimos años sobre la represión política en este período.

En un primer momento, se realizará un breve repaso sobre las leyes y decretos confeccionados y aplicados durante el periodo 1958-1962. En un segundo momento, se analizarán las fuentes documentales correspondientes a los debates dentro de la Cámara de Diputados de la Nación acerca de la problemática en torno a los detenidos por motivos políticos. En tercer lugar, se presentarán los dos tipos de detenidos que este trabajo plantea, intentando sistematizar las características de las detenciones y la situación carcelaria en cada caso. Aquí, a través de las fuentes documentales utilizadas, afirmamos la existencia de "procedimientos" de detención y "circuitos" de traslado que se aplicaban de modo general a la mayoría de los perseguidos políticos. Planteamos que tales formas y circuitos diferían dependiendo de si se trataba de perseguidos políticos por pedido del Poder Ejecutivo o si se los perseguía bajo el Plan Conintes.

Siguiendo este hilo argumentativo, instrumentadas a través de distintas medidas de excepción, afirmamos que las detenciones en clave de represión política fueron una constante durante el gobierno de Frondizi. Así, partimos de la premisa de que las cárceles constituyeron un factor central del engranaje por medio del cual el gobierno lidiaba con la oposición - particularmente el peronismo y el comunismo- e intentaba controlarla. ${ }^{2}$ En la utilización diferencial de distintas unidades carcelarias según el "tipo" de detenido político, en las formas de detención y los "circuitos" de traslado constantes de muchos presos, en la aplicación de torturas, se puede advertir el rol central que ocuparon las instituciones de encierro durante el frondicismo. En el mismo sentido, la hipótesis del trabajo es que el estudio, tanto de los lugares y las instituciones donde fueron encarcelados los militantes peronistas y comunistas como de los procedimientos empleados para su detención durante la presidencia de Frondizi, contribuirá a arrojar luz sobre las prácticas represivas empleadas desde el Estado y sus instituciones en dicho período. Se busca de este modo reflexionar sobre la historia institucional argentina intentado aportar al estudio de las distintas prácticas autoritarias y de represión política, a partir de una mirada desde las instituciones de encierro y desde los actores comprometidos en los procesos de detención.

En lo que se refiere al estudio de las instituciones de encierro en relación a la represión política durante el período aquí estudiado, nos encontramos frente a un campo de estudios que aún no se ha consolidado. Con esto queremos decir que han comenzado en los últimos años algunas investigaciones destinadas al análisis de la represión política y, sobre todo, focalizadas en el rol que comienzan a asumir desde fines de los años cincuenta las fuerzas armadas dentro de la seguridad interna del país (Summo y Pontoriero, 2012; Pontoriero, 2017; Chiarini y Portugheis, 2014; Fayó, 2005 y 2007; Franco, 2012; Seveso, 2009). Sobre este último punto, los avances han sido significativos. Sin embargo, y a pesar de que los primeros trabajos sobre la represión política durante Frondizi han llegado a conclusiones concretas sobre los fuertes niveles de persecución y la inauguración de todo un nuevo corpus legislativo en torno a la misma, en el área de estudios sobre las instituciones de encierro y los detenidos políticos nos encontramos con un ámbito que ha sido poco explorado. De esta manera, son muy escasos los estudios que toman a las cárceles y otros lugares de detención como el foco de análisis. Además, y como lo comprueba una reciente actualización sobre el estado de los estudios de las prisiones en América Latina hasta la fecha, el énfasis en el estudio de los presos políticos constituye un campo de estudios en formación que ha comenzado en las últimas dos décadas (Salvatore y Aguirre, 2017). En resumen, el estado del arte indica que dichos estudios están abocados a las experiencias de los presos políticos y, sobre todo, en períodos dictatoriales. Sostenemos que dicha línea de investigación podría verse enriquecida con trabajos académicos abocados a períodos no dictatoriales.

Para contextualizar, existen estudios y escritos testimoniales que comprueban que a partir del primer peronismo las cárceles comenzaron a ser utilizadas como un recurso sistemático y central en las políticas 
de persecución del disidente político (Kohen, 1980; Plater, 1956; Lafiandra, 1955; Ruiz Moreno, 1994). ${ }^{3}$ En efecto, una evidencia de dicha utilización la conforma el hecho de que dicho gobierno modificó las normativas del sistema carcelario de forma tal que el Estado pasó a tener más poder de decisión e influencia sobre las cárceles provinciales. ${ }^{4}$ Luego de la caída del peronismo en 1955, los años del extremo antiperonismo de la Revolución Libertadora se caracterizaron en parte por el gran consenso entre distintos sectores de la sociedad -civiles, militares, policiales, con el apoyo de los medios- detrás del objetivo de eliminar al partido y la militancia derrocada del gobierno. Apoyado por esta gran coalición de fuerzas, el gobierno de facto se caracterizó por la represión ilegal y el uso de las instituciones del Estado al servicio de la persecución política del peronismo. De esta manera, la Revolución Libertadora combinó métodos ilegales de represión con el esfuerzo por otorgarle a dicha persecución del peronismo un marco legal a través de numerosos decretos y leyes. En este contexto, las cárceles se convirtieron también en un espacio donde el Estado intentó controlar a los militantes y desarticular al peronismo (Seveso, 2009). Así, la reapertura del penal de Ushuaia para el encarcelamiento de presos políticos, que había sido clausurado por el peronismo, constituyó un símbolo de la lógica de represión estatal.

Ahora bien, las fuentes documentales de la Cámara de Diputados de la Nación y los casos investigados por la Comisión de Supuestos Apremios Ilegales nos muestran que durante el período democrático inaugurado por Arturo Frondizi luego de la Revolución Libertadora, los detenidos políticos y, en consecuencia, las instituciones de encierro ocuparon un lugar central en las políticas desplegadas por el gobierno. Vale aclarar que los métodos de persecución política van a transformarse ya que, como explican otros autores, al tratarse de un período democrático, se debió hacer uso de herramientas legales de excepción para habilitar la misma. De esta manera, el Poder Ejecutivo encontró en la detención por motivos políticos y supuestamente también subversivos una manera de lidiar con la oposición. La problemática de las detenciones políticas así como también las irregularidades ocurridas en los procesos de detención y las torturas a presos se tornaron un tema protagónico en los medios de comunicación y en la opinión pública. Como veremos más adelante, a raíz de esta visibilidad, y de las cada vez más numerosas denuncias sobre apremios ilegales sufridos por los detenidos políticos, se conformó en la Cámara de Diputados de las Nación una Comisión Especial Investigadora de Supuestos Apremios Ilegales. De este modo, las principales fuentes utilizadas en esta investigación corresponden a los debates de la Honorable Cámara de Diputados de la Nación en los años 1960 y 1961, así como las denuncias investigadas por la Comisión Especial Investigadora de Supuestos Apremios Ilegales.

\section{ConteXto LEgal REPRESIVO DURANTE EL FRONDICISMO}

Durante el período de la presidencia de Arturo Frondizi, el Estado desplegó una serie de medidas legales que tenían por objetivo la represión política de la oposición. Como explican otros autores, a varias de estas leyes o decretos puede cuestionársele su nivel de legitimidad ya que iban en contra de las garantías constitucionales o se basaban en legislaciones anteriores, forzando al máximo la interpretación de las mismas para legislar nuevas medidas represivas. ${ }^{5}$ Aquí explicaremos brevemente dicho marco legal ya que resulta indispensable para esta investigación y su interpretación.

$\mathrm{Al}$ asumir su mandato el presidente decretó el día 25 de mayo de 1958 la Ley de Amnistía general "para todos los delitos políticos, comunes conexos o militares también conexos” en el territorio argentino (Ley 14.436, 1958). ${ }^{6}$ Uno de los fundamentos que expresaba el Ejecutivo era la necesidad de "vivir en plenitud un estado de derecho". ${ }^{7}$ Casi seis meses después, en un clima de agitación política desatado en la provincia de Mendoza contra las medidas económicas del gobierno, declaró el estado de sitio en todo el territorio. Es importante resaltar que un mes más tarde, ante el pedido del presidente, el Congreso prorrogó el estado de sitio por tiempo indeterminado hasta que "desaparezcan las circunstancias que hacen necesaria su sanción". 8 
De esta manera, justificado por medio de esa vaga afirmación donde no se especifican las circunstancias a las que alude, el país quedó bajo una situación política donde los poderes del Ejecutivo se veían aumentados en tanto que las garantías individuales quedaban reducidas. Esto perduró hasta el final de la presidencia de Frondizi, por lo cual el presidente contó, desde octubre de 1958 hasta el final de su mandato, con la autoridad para arrestar y trasladar personas que considerase por algún motivo amenazantes al orden y la paz de la Nación. Como veremos más adelante, de allí en adelante y hasta el final del período frondicista, se ordenó la detención de miles de militantes de la oposición. ${ }^{9}$ Estos constituyen uno de los tipos de detenidos analizados en esta pesquisa.

A su vez, tres días más tarde de la primera aplicación del Estado de sitio, el Ejecutivo puso en vigencia mediante decreto secreto el Plan Conintes. ${ }^{10}$ Aquí el gobierno justificó la imposición del estado de sitio afirmando que existían "elementos políticos, notoriamente antidemocráticos (...) que intentan crear en el país una situación de anarquía y subversión”. ${ }^{11}$ Por su parte, el Plan Conintes declaraba el estado de Conmoción Interior y estipulaba que las policías provinciales quedaban subordinadas a las fuerzas armadas. Sin embargo, la escalada de la conflictividad social no cesó, y el día 13 de marzo de 1960 el Poder Ejecutivo sancionó el decreto 2628, que consistía en la aplicación pública del Plan Conintes. A partir de aquí, se llevó a la práctica la subordinación de las policías a las autoridades militares. Vale realizar un paréntesis y aclarar aquí que la sanción del Plan Conintes se apoyó en la Ley de Organización de la Nación en Tiempos de Guerra promulgada, paradójicamente, por el gobierno peronista en el año 1948. Sin ahondar en detalles, en sus artículos más importantes (art. 14, 17, 18, 27, 28 y 30) se disponía la división del territorio en zonas que el Poder Ejecutivo en tiempos de guerra podía declarar como zonas de jurisdicción militar. Siguiendo la misma lógica, la ley contemplaba que en caso de emergencia grave o por causa de guerra el Poder Ejecutivo podía movilizar a la población de las regiones afectadas, quedando los ciudadanos sujetos a la justicia militar. ${ }^{12}$ Sin embargo, vale remarcar que tal ley del peronismo fue pensada para los casos de ataque exterior, en términos de guerra convencional. Ya otros autores han mencionado esta lógica del gobierno de Frondizi tendiente a manipular la interpretación de las disposiciones legales ya vigentes con el fin de poder sancionar otras apoyándose en la legislación disponible y lograr una militarización de la represión hacia el interior del país. ${ }^{13}$

Dos días después de la ejecución pública del Plan Conintes el Ejecutivo dictó el decreto 2639/60 donde declaraba la situación de "emergencia grave" en el país, estipulada en la mencionada ley 12.234 , desatada a partir de manifestaciones que el gobierno consideraba como intimidación pública y terrorismo. ${ }^{14}$ Este último decreto dejaba bajo jurisdicción militar a los acusados de tales actos y ordenaba la constitución de Consejos de Guerra por parte de los comandantes de las fuerzas armadas, según lo establecido en el Código Militar, para su juzgamiento. Con la implementación del Plan Conintes encontramos al segundo grupo de perseguidos y detenidos, cuya persecución, encarcelamiento y juzgamiento quedaron a cargo de los militares.

El Estado, a través de las fuerzas armadas y de las policías subordinadas a ellas, detuvo a centenares de personas desde marzo de 1960 hasta el primero de agosto de 1961, fecha de su derogación. No obstante, las causas y delitos que habían sido consumados bajo su vigencia continuaban bajo jurisdicción militar. Además, es importante remarcar que luego de la finalización del Plan Conintes el gobierno volvió a declarar en varias oportunidades la situación de "emergencia grave" en distintas ramas de la producción y transporte, a través de la cual se volvió a autorizar a las fuerzas militares a proteger "los objetivos esenciales para la vida nacional". ${ }^{15}$

A través de toda esta estructura de decretos y leyes, el gobierno frondicista detuvo y encarceló a miles de opositores políticos, justificándose en el hecho de que tales personas constituían un peligro para la paz social del país o, incluso, una fuerza subversiva. 


\section{Formación de la “Comisión Investigadora de Supuestos Apremios Ilegales”}

El día 20 de julio de 1960 se presenta a la Cámara de Diputados de la Nación un proyecto de resolución con el objeto de solicitar al Poder Ejecutivo Nacional un informe sobre la situación de 14 detenidos por causas políticas en la ciudad de La Plata. Dicho proyecto se refería a personas que habían sido detenidas con posterioridad al día 14 de marzo del mismo año, fecha en la cual el presidente de la República había decretado la aplicación pública del Plan Conintes. Al día siguiente, el Poder Ejecutivo promulgó también el decreto 2639 de Represión del Terrorismo. A partir de allí, aumentó considerablemente la cantidad de denuncias sobre apremios ilegales y detenciones por fuera de las normas legales. De esta manera, distintos diputados nacionales de los dos bloques mayoritarios, la Unión Cívica Radical Intransigente y la Unión Cívica Radical del Pueblo, comenzaron a encargarse de indagar en tales casos denunciados. ${ }^{16}$ Sus principales reclamos se fundamentaban en que incluso en los casos en donde presos no eran de origen Conintes, sino detenidos a disposición del Poder Ejecutivo por motivos políticos o gremiales, eran víctimas de tales situaciones a manos de las fuerzas de seguridad. El proyecto mencionado fue presentado por el Diputado Antulio Pozzio, uno de legisladores más destacados de la Unión Cívica Radical del Pueblo.

Ya el día 22 de junio de 1960 este proyecto había sido aprobado por la Comisión de Asuntos Constitucionales y solicitaba que el Presidente de la Nación, por medio del Ministerio del Interior, informe sobre la disposición por medio de la cual se los mantenía detenidos y los hechos que justificaban su detención. A su vez, se reclamaba que dichos presos, que para la fecha se encontraban detenidos en Olmos, no podían ser visitados por sus abogados y que existía la posibilidad de que hayan sido objeto de apremios ilegales. Por otra parte, los legisladores pedían que se informe sobre cuál sería el próximo destino de los detenidos y requerían, en caso de haber sido encarcelados por "subversivos", que se determine bajo qué disposición legal se realizó tal detención. Por último, el proyecto de resolución dejaba en claro que si bien la justicia había decretado la libertad por falta de mérito de algunos de ellos, a la fecha continuaban detenidos "por orden del Poder Ejecutivo". 17

Durante la presentación del proyecto, el diputado Pozzio enfatizó en el hecho de que a pesar de haber visitado los lugares de detención en busca de respuestas, no había conseguido esclarecer ninguno de los puntos que plantea el proyecto. En su exposición sobre estas irregularidades respecto de los detenidos reclama también la situación de otro detenido político que había sido juzgado por la justicia militar y luego sobreseído pero que, sin embargo, aún se encontraba privado de su libertad a disposición del Poder Ejecutivo.

Dicho reclamo al Poder Ejecutivo sobre la detención y condiciones de presos políticos no era nuevo en la Cámara. Al respecto se habían tratado ya varias iniciativas en la Comisión de Asuntos Constitucionales, reclamando respuestas al Ministerio del Interior y al Poder Ejecutivo sobre estos temas. Otro diputado de la UCRP, Carlos H. Perette, subrayaba en esa misma reunión de la Cámara que "las detenciones por causas políticas y gremiales en los dos años de este gobierno han asumido proyecciones y trascendencia inigualadas, sobre todo en el año 1959 y en los meses transcurridos de 1960". ${ }^{18}$ En su discurso hizo también alusión a una lista de casi 150 personas detenidas sin proceso. De la misma manera, surgieron denuncias en torno a los abusos practicados por personal militar y policial que respondía al Plan Conintes, donde se hacía hincapié en los abusos de autoridad y en las torturas aplicadas a dichos presos. ${ }^{19}$ Estas son solo algunas de las tantas denuncias que llegaban a los legisladores a través de familiares y compañeros de trabajo de los detenidos bajo situaciones poco claras. Por otra parte, y como punto central, todas estas denuncias hacían referencia a apremios ilegales o torturas a los detenidos.

Hasta aquí, podemos afirmar que hacía ya algún tiempo que los diputados de la Unión Cívica Radical del Pueblo proponían la conformación de distintas comisiones parlamentarias para recibir y considerar todas las denuncias de esta índole, pero dichos proyectos se veían obstaculizados por el sector de la mayoría. ${ }^{20}$ Varios de los diputados nacionales (sobre todo los de la oposición) venían ya realizando un trabajo de campo respecto 
de este tema. Llevaban adelante investigaciones tanto en torno a procesos ilegales de detención de personas por motivos políticos y gremiales o bajo el Plan Conintes, como en relación a las condiciones en que dichos detenidos se encontraban y los apremios ilegales o torturas que posiblemente sufrían. Estas investigaciones incluían la visita de detenidos en distintas cárceles y comisarías del país así como entrevistas a familiares y compañeros de los mismos. En este sentido, y al menos desde el mes de mayo de 1960, tanto la postura del Poder Ejecutivo como el accionar de los miembros de las fuerzas de seguridad respecto de los detenidos políticos constituían una problemática que se encontraba sobre el tapete en la Legislatura Nacional. De la misma manera, la cuestión había adquirido en el último tiempo visibilidad pública, ya que los periódicos más relevantes de la época la seguían de cerca. ${ }^{21}$

Es en este contexto, donde la problemática de las torturas constituía ya un tema prioritario en los debates y en la opinión pública, que surgió la propuesta de constituir una comisión investigadora dedicada exclusivamente al manejo e investigación de aquel tipo de denuncias. No obstante las reticencias hasta el momento del bloque de la mayoría a aceptar la existencia de acciones ilegales por parte de las fuerzas policiales y, sobre todo, de las Fuerzas Armadas, la iniciativa fue presentada por el diputado de la UCRI Gómez Machado. De esa forma, el día 21 de julio se aprobó el proyecto de resolución por el cual sancionó la conformación de una Comisión Investigadora de Supuestos Apremios Ilegales. ${ }^{22}$ La misma se desempeñaría hasta el 30 de septiembre de 1960, quedando a consideración la posible prórroga de su mandato en caso de ser considerada necesaria por la Cámara de Diputados. Sus funciones estaban enfocadas a la investigación de las denuncias sobre supuestos apremios ilegales a detenidos, tanto políticos como comunes, ${ }^{23}$ para luego elevar los resultados de tales estudios a la justicia.

La Comisión funcionó oficialmente hasta el 30 de junio de 1961. Con anterioridad a esa fecha se le otorgaron varias prórrogas, justificadas por los diputados en función a la gran cantidad de denuncias que continuaban recibiendo. No obstante, hacia junio de 1961, en un contexto de recrudecimiento de la situación de los detenidos políticos y visibilidad mediática del asunto, sorpresivamente el grueso del bloque de la mayoría votó esta vez por la negativa a una nueva prórroga. Vale aclarar que en aquellos días se desarrollaban acalorados debates alrededor de la responsabilidad del Poder Ejecutivo y de las fuerzas de seguridad en relación a los presos políticos y presos Conintes, y los procedimientos de encarcelamiento y las condiciones de encierro de los mismos. Así, la problemática había adquirido gran trascendencia en la opinión pública y se agudizaba también al interior de la Cámara. ${ }^{24}$ Esto se debía en gran parte a que las pericias realizadas por diputados de la oposición ya estaban dando resultados contundentes en materia de pruebas recolectadas e informes parciales que emitía la Comisión Investigadora, poniendo la lupa sobre todo en las detenciones políticas. De esta manera, algunos diputados hacían sentir sus conclusiones en el recinto afirmando que, en materia de presos políticos -incluidos los detenidos por el Plan Conintes- el derecho y las garantías constitucionales estaban "aniquiladas". ${ }^{25}$ En contraposición a estas afirmaciones, algunas voces del oficialismo eximían de responsabilidad a las autoridades militares y al Presidente de la Nación. En este contexto, y con la denuncia de los diputados de la oposición acerca de la injerencia y complicidad del Poder Ejecutivo en la toma de esta decisión, la Comisión llega a su fin.

Durante su año de existencia, la Comisión Investigadora de Presuntos Apremios Ilegales recibió más de 350 denuncias, de las cuales gran parte se referían a presos políticos y a presos Conintes. A su vez, los diputados miembros tomaron más de 2000 declaraciones a presos y testigos, recorrieron cárceles y otras instituciones a lo largo del país en donde se alojaban las presuntas víctimas, en pos de relevar testimonios y comprobar también las condiciones de los establecimientos penitenciarios.

La aproximación a los debates de la Cámara de Diputados de la Nación durante el período de funcionamiento de la Comisión Investigadora de Supuestos Apremios Ilegales, y a los legajos sobre las denuncias investigadas por la misma, nos permite un acercamiento, aunque sea a modo general, a la problemática de las detenciones políticas y a las prácticas represivas llevadas a cabo por las fuerzas policiales 
y militares en aquellos años. A su vez, estos reservorios documentales constituyen una riquísima fuente para indagar sobre las políticas de utilización de las cárceles y otros destinos de detención de los presos políticos, así como sobre el lugar que han ocupado las mismas como parte del engranaje represivo estatal. La función específica de la Comisión era la investigación de apremios ilegales una vez que las personas se encontraban detenidas. Ahora bien, las prácticas de detención y el rol de las autoridades policiales o militares a cargo de las mismas constituían temas imposibles de desligar de aquel objetivo. A su vez, vimos cómo dentro de la propia Cámara se mencionaba a los tipos de detenidos políticos que eran perseguidos bajo distintas leyes o decretos propios del período frondicista. A continuación, analizaremos algunos aspectos particulares acerca de las detenciones y el rol de las cárceles a partir de los debates suscitados en la Cámara de Diputados.

\section{Detenciones a Disposición Del Poder Ejecutivo: ACtores, circuitos, PROCEDIMIENTOS}

Como mencionamos anteriormente, el 11 de noviembre de 1958, a los seis meses del comienzo del mandato de Arturo Frondizi, a través de la Ley 14775 se declaró el estado de sitio en todo el país por un término de treinta días. Un mes más tarde, cumplido dicho plazo, se sancionó la ley 14785 que continuaba la aplicación del estado de sitio por tiempo indeterminado. De esta manera, entre finales de 1958 y hasta la caída de Frondizi en 1962, miles de trabajadores y militantes quedaron tras los muros como consecuencia de decenas de decretos que ordenaban la detención de personas a disposición del Poder Ejecutivo por motivos políticos. Aclaremos aquí que, bajo el Estado de sitio, el gobierno de turno está autorizado a detener personas a su disposición y al traslado de las mismas. Ante esta situación, en los debates sobre la aprobación por parte de la Cámara de Diputados de la Nación de dicha prórroga por tiempo indeterminado, los legisladores de las minorías expresaron su oposición a tal medida por considerar que el Estado no había podido justificar la declaración de emergencia como también por afirmar como una estrategia del gobierno para resolver los problemas con la disidencia política. ${ }^{26}$

Ya en los primeros días de vigencia del estado de sitio, el Poder Ejecutivo ordenó la detención de más de 600 personas. ${ }^{27}$ El estado de sitio se prolongó hasta la caída del presidente Arturo Frondizi, lo cual implicó que dicho instrumento del gobierno, originalmente concebido como herramienta de excepción, se transformara en una constante del gobierno frondicista. Como explica Marina Franco, esta medida adoptó un "carácter preventivo", puesta en práctica con el objetivo de controlar futuras movilizaciones o actividades políticas que pudiesen desestabilizar, a los ojos del gobierno, el orden interno. ${ }^{28}$ Vale subrayar aquí que en la historia argentina la utilización de este recurso como forma de lidiar con la disidencia política corresponde a una larga tradición jurídica. Así lo expresaba el senador Alfredo Palacios durante una de las sesiones de la Cámara de Senadores, en mayo de 1958, al discutir sobre los detenidos a disposición del Poder Ejecutivo o de autoridades militares y las torturas infringidas al afirmar su angustia por "tener que denunciar en esta misma banca lo mismo que hace treinta años” (Rodríguez Molas, 1985, p. 205).

No obstante, la represión y utilización de estas estrategias registran un salto en cantidad y fuerza a partir de la Revolución Libertadora y su intención de “desperonizar” el país (Seveso, 2009). A través de la descripción y análisis de la política de encarcelamiento a disposición del Poder Ejecutivo durante el gobierno de Frondizi, pretendemos visibilizar la continuación de aquella política de la Libertadora de persecución de la oposición y la consecuente utilización regular y masiva de dicho recurso ahora por parte de un gobierno constitucional.

Para la comprensión global de este tema y de la dinámica general de funcionamiento de las prisiones nacionales, es necesario señalar la promulgación del Decreto $\mathrm{N} .^{\circ} 412$, que aumentaba la capacidad de intervención del Poder Ejecutivo sobre el sistema penitenciario del país. ${ }^{29}$ El mismo fue dictado en enero de 1958, aún bajo el gobierno de facto de la Revolución Libertadora. Establecía la unificación legal de las normas penitenciarias de las provincias, ajustadas a la legislación penitenciaria nacional. A partir de este decreto, 
la Dirección Nacional de Asuntos Penales quedaba habilitada a "pedir información, inspeccionar, trasladar reclusos bajo jurisdicción provincial” (Silva, 2012, pp. 16-17).

Por otro lado, en los documentos analizados son reiteradas las denuncias de tortura hacia este tipo de presos. De hecho, aparecen mencionadas en la gran mayoría de los casos. Sostenemos entonces que la aplicación de torturas hacia los recluidos a disposición del Poder Ejecutivo se tornó parte regular del tratamiento de los mismos.

Como última aclaración en cuanto a su implementación, es importante remarcar que la detención de personas a disposición del Poder Ejecutivo constituyó una constante durante el gobierno de Arturo Frondizi. Dichas detenciones, justificadas bajo la necesidad de "asegurar la tranquilidad pública”, se ordenaban a través de decretos presidenciales y la institución de seguridad a cargo de su implementación era la Policía Federal. ${ }^{30}$

En primer lugar, a través del planteo de ciertas denuncias de apremios ilegales se hace referencia a las prácticas llevadas a cabo desde el momento de la detención hasta que la persona llegaba finalmente al destino donde quedaría encarcelado. Con esto nos referimos a que se podrían establecer ciertas etapas, una especie de "recorrido" por el que pasaban los detenidos antes de arribar a la unidad penitencia nacional donde quedarían formalmente encarceladas.

La mayoría de los detenidos no eran enviados directamente al lugar donde serían encarcelados. Es decir, solían ser trasladados a varios destinos antes de llegar a la institución final donde esperarían cumplir la condena. Sin quedar registrado en los documentos de las fuerzas de seguridad, los detenidos políticos primero solían ser llevados a lugares donde se les realizaban interrogatorios o eran sometidos a torturas o malos tratos. En varios de estos casos, las autoridades les negaban el conocimiento del lugar en el que se encontraban así como también las causas por las cuales eran retenidos allí. Los diputados encargados de realizar las indagaciones correspondientes a las denuncias de torturas y detenciones ilegales afirmaban que eran comunes los traslados de los detenidos políticos de una comisaría a otra antes de llevarlos a las unidades carcelarias. ${ }^{31}$ Según los documentos consultados, este confuso camino de traslados hasta llegar finalmente a una unidad carcelaria era conocido con el nombre de "giro". ${ }^{32}$ Es importante subrayar que en las denuncias que llegaban a la Comisión Investigadora el traslado a lugares indeterminados para la aplicación de torturas era un común denominador. Principalmente estos traslados clandestinos a los sitios donde serían víctimas de torturas se realizaban desde la primera dependencia - no desde la cárcel- a la que la policía llevaba a los detenidos a disposición del Poder Ejecutivo.

Profundizando en la caracterización de las detenciones, encontramos que en el caso de las personas detenidas por causas políticas y gremiales se denunciaban repetidamente varias irregularidades respecto del proceso de detención y las condiciones de la misma. Las autoridades policiales solían irrumpir en horas de la madrugada en las casas de las personas que tenían orden de detener, sacándolas de su domicilio sin dar explicación acerca de la justificación de la detención. En el mismo sentido, tampoco se solían especificar las causas de las detenciones una vez que el detenido se encontraba en prisión. Todo esto queda en evidencia en distintas averiguaciones que realizaban los diputados solicitando a las autoridades policiales y carcelarias dicha información, o reclamando al Ministerio del Interior cuando no recibían respuesta de aquellas autoridades -la demora en las respuestas era frecuente-. Dichos reclamos enfatizaban en la especificación tanto de los decretos o leyes como de los hechos concretos bajo los cuales la detención se justificaba.

Otra irregularidad frecuente se relaciona con el hecho de que los detenidos eran retenidos injustificadamente en las instituciones carcelarias. Esta fue la situación de muchas personas puestas a disposición del Poder Ejecutivo que luego eran sobreseídas por "falta de mérito", pero aun así continuaban encarceladas sin motivo que lo justifique. Lo mismo ocurría con muchos otros detenidos sin proceso abierto ni causas que justifiquen su encarcelamiento, a los cuales no se les hacía efectiva la libertad. ${ }^{33}$

Indagando en los documentos acerca de los lugares de detención de los presos a disposición del Poder Ejecutivo, nos encontramos con otro dato que aportaría a la lógica de estos circuitos de traslado que hemos caracterizado. Generalmente, luego del paso por varias dependencias policiales, los detenidos políticos y 
gremiales solían quedar ubicados en unidades carcelarias lejanas a su lugar de residencia y del sitio donde los habían apresado. Incluso se desprende de los documentos que en los casos donde se apresaban a varias personas que compartían militancia, o que eran detenidas bajo una misma causa, solían alojarlas en distintos destinos carcelarios. Este fue, por ejemplo, el caso de 41 obreros plomeros detenidos en 1959 a disposición del poder ejecutivo, quienes aún un año después continuaban encarcelados y divididos, algunos en la Penitenciaría Nacional y otros en la cárcel de Santa Rosa. Estos traslados no eran a voluntad de las autoridades policiales ni carcelarias, sino que eran ordenados a través de decretos dictados por el Poder Ejecutivo, amparándose en el estado de sitio que le otorgaba dicha facultad. Así, el Poder Ejecutivo ordenaba su traslado a unidades carcelarias alejadas del lugar de residencia de los presos. De esta manera, muchas veces a través del traslado desde la provincia de Buenos Aires a la provincia vecina de La Pampa, se recluía a los detenidos en una institución carcelaria alejada de sus hogares.

Ahora bien, a la hora de definir a los responsables de dichas prácticas ilegales, la Policía -tanto Federal como en algunos casos las policías provinciales-era la institución más señalada por las autoridades legislativas. Por consiguiente, y por los motivos que explicamos anteriormente sobre la relación de la prensa con las investigaciones de la Comisión, también la opinión pública llevaba al día estos hechos y ponía al descubierto las consecuentes malas prácticas de las fuerzas de seguridad policiales. A este respecto, para el caso de la Policía de la Provincia de Buenos Aires, los primeros años de la década de 1960 constituyeron una coyuntura de agudización del empleo de violencia y torturas. La fuerte persecución política, con cientos de personas a quienes el Poder Ejecutivo ordenaba detener sumado a la aplicación del Plan Conintes, generó que aquellos "recursos" que la policía ya venía desplegando en el ámbito de la justicia ordinaria estuvieran ahora disponibles para ser aplicados en la represión política (Barreneche, 2012, p. 21). Es así que en este panorama de aumento de la persecución a la disidencia política encontramos que en la mayoría de las denuncias sobre procedimientos ilegales de detención y abusos de autoridad había, entre los señalados como responsables, miembros de las fuerzas policiales. Para ahondar más en esta temática, podemos decir que al menos desde julio de 1960 la premisa de que la tortura por parte de las fuerzas policiales -y, como veremos, militarescomo método para "arrancar declaraciones" constituía una realidad en la coyuntura política argentina era aceptada por la mayoría de los legisladores y constituía uno de los temas de discusión primordiales en los debates de las legislaturas provinciales. ${ }^{34}$ Prueba de ello es la conformación de Comisiones investigadoras de apremios ilegales y torturas en las legislaturas de Buenos Aires y Mendoza. ${ }^{35}$ Esto se debía en parte al trabajo de campo realizado por algunos de los diputados - como Baigorria, Luelmo y el ex diputado León- donde se comprobaron varias irregularidades respecto a las detenciones de presos políticos y gremiales, detenidos a disposición del Poder Ejecutivo. ${ }^{36}$ Los diputados afirmaban en el recinto que, a partir de averiguaciones y visitas a la cárcel de Caseros, pudieron confirmar tanto procedimientos ilegales de detención y traslados como torturas. Aseveraban incluso que los informes médicos daban cuenta de la utilización de la picana eléctrica como parte de los métodos de tortura. En cuanto a la modalidad de las detenciones, enfatizaban en el hecho de que las personas eran sacadas a la fuerza de sus casas y trasladadas a distintos destinos - de los cuales no se los informaba ni a ellos ni a sus familias- hasta llegar a la cárcel. Estos traslados perpetrados por fuera de la legalidad, denunciaban, solían ser realizados por el personal de la Policía Federal o, en ocasiones, los detenidos eran entregados a personas desconocidas que llevaban adelante los actos de tortura. Un año más tarde, la diputada de la UCRI Nélida Baigorria hacía un balance de los años transcurridos - donde recordaba también el caso de la cárcel de Caseros- y afirmaba que existía un "procedimiento sistematizado". 37

En síntesis, las fuerzas de seguridad policiales - tanto a nivel nacional como provincial- sobresalían como principales autoridades responsables de la perpetración de apremios ilegales en las modalidades de detención y encarcelamiento de los militantes políticos puestos a disposición del Poder Ejecutivo. A la valoración negativa que de ellas existía en la prensa ya antes de estos acontecimientos, ahora se sumaban las denuncias relacionadas con su accionar represivo contra las miles de personas que el Poder Ejecutivo les ordenaba detener por motivaciones políticas a través de incontables decretos presidenciales. 
Siguiendo este hilo argumentativo, sabemos que las fuerzas armadas también eran acusadas de abusos de autoridad y accionar ilegales, pero su accionar y responsabilidad fueron cuestionados en los procedimientos de detención y trato a los detenidos catalogados como subversivos, es decir, bajo el Plan Conintes. La aplicación del mismo, con el consecuente protagonismo que otorgó a las fuerzas armadas, llevó a que no solo se culpe en estos casos a las fuerzas policiales. Como analizaremos a continuación, existieron denuncias sobre abusos de poder a la hora de las detenciones así como también de torturas a los presos Conintes.

\section{Detenciones Conintes: ACTOREs, Circuitos, PROCEDIMIENTOS}

Como ya hemos descripto, desde la sanción pública del Plan Conintes y de la declaración de emergencia grave - 13 y 15 de marzo de 1960 - el gobierno ordenó numerosas movilizaciones masivas de personal de distintos gremios en todo el país. Como consecuencia, en estas regiones controladas ahora por las autoridades militares, se ordenó la detención de cientos de militantes bajo la premisa de estar vinculados a supuestos actos de terrorismo. Sabemos también que los presos Conintes, de acuerdo con el decreto 2639 que declaraba jurisdicción militar sobre los delitos de intimidación pública y terrorismo, eran juzgados por tribunales militares. ${ }^{38}$ Aquí el protagonismo en la represión política ya no sería de las fuerzas policiales, sino que estas actuarían en conjunto -y subordinadas- a las autoridades militares. Es en este contexto que las fuerzas armadas, durante un gobierno no dictatorial, adoptaron un rol central y permanente no solo en la represión política interna del país sino también en el juzgamiento y encarcelamiento de las personas sospechadas de terroristas. En este sentido, dentro de la Legislatura se generaron en la oposición intensas resistencias frente a esta legislación represiva puesta en marcha por el Poder Ejecutivo. En ambas Cámaras se presentaron proyectos relacionados a declarar la nulidad de la ley 12.234 de Organización de la Nación para Tiempos de Guerra y de todos los decretos que de ella se desprendían. Los legisladores de la oposición fundamentaban sus reclamos principalmente en el artículo 29 de la Constitución Nacional, que sostiene que "el Congreso no puede conceder al Ejecutivo Nacional (...) facultades extraordinarias, ni otorgarle sanciones o supremacías". En este sentido, argumentaban que la ley marcial violaba expresamente el texto constitucional. Dichos proyectos reclamaban la libertad de los detenidos Conintes, por entender inconstitucional el juzgamiento de civiles por tribunales militares. ${ }^{39}$

Existen ya trabajos de investigación que analizan el rol desempeñado por las fuerzas armadas durante la puesta en marcha del plan Conintes, pero no así sobre los procedimientos de detención y el rol ocupado por las cárceles como parte de la aplicación del mismo. ${ }^{40}$ En este apartado intentaremos aportar algunas posibles líneas de investigación al respecto.

Como hemos mencionado, la Comisión Investigadora de Supuestos Apremios Ilegales siguió de cerca la investigación de muchos casos de apremios ilegales a presos Conintes. Al igual que ocurrió con las investigaciones respecto de los presos a disposición del Poder Ejecutivo, los diputados de la Comisión realizaron numerosos viajes y visitas a dependencias de las fuerzas armadas y unidades carcelarias de todo el país en busca de la clarificación de los hechos de tortura e irregularidades denunciados. Entre las actividades principales desarrolladas por los diputados miembros de la Comisión, encontramos entrevistas tanto con presos Conintes, familiares, testigos y profesionales médicos como con autoridades militares, policiales y carcelarias. De este modo, la aplicación del Plan Conintes, el debate sobre la constitucionalidad o no de su aplicación y el rol desempeñado por las autoridades involucradas en las detenciones de los supuestos terroristas, adquirieron gran protagonismo en los debates de la cámara en los años 1960 y 1961. Estos debates y la actividad de la Comisión nos permiten también, como vimos en el caso de los presos políticos y gremiales puestos a disposición del Poder Ejecutivo, establecer ciertos parámetros o modalidades en los procedimientos de detención de los presos Conintes. 
En primer lugar, podemos establecer también aquí cierto "circuito" de traslados de los presos Conintes. Las detenciones eran realizadas tanto por personal militar como por personal de la policía Conintes, bajo órdenes de los primeros. Podemos dividir el circuito en distintas etapas registradas para la mayoría de los casos denunciados. En un primer momento, eran trasladados a dependencias de las Fuerzas Armadas dentro o cercanas a la zona militarizada donde se producía la detención. Se trataba de instituciones propias de la fuerza -entre las que se destacan Campo de Mayo, la Escuela de Mecánica del Ejército, el Regimiento de Patricios de la Capital y distintas Bases Navales--. A diferencia de los presos políticos y gremiales a disposición del Poder Ejecutivo, solo existía un primer traslado a la comisaría o dependencia policial en el caso de que las detenciones hubieran sido llevadas a cabo por personal policial. A partir de este primer destino próximo al lugar de detención, en algunos casos se registra que los presos Conintes eran luego trasladados a pabellones de distintas unidades penitenciarias que se encontraban intervenidos por las autoridades militares expresamente para el alojamiento de los mismos. Estos sectores destinados a detenidos Conintes quedaban bajo jurisdicción militar y eran administrados y controlados por las fuerzas armadas, que también supervisaban a los detenidos y manejaban en los pabellones la información sobre los mismos. Los documentos muestran que, por ejemplo, en distintas oportunidades la Comisión Investigadora solicitaba informes sobre detenidos Conintes al Jefe de la Penitenciaria Nacional de la Capital, sin conocer este detalles sobre los presos Conintes alojados en el pabellón n. ${ }^{\circ}$, administrado directamente por las fuerzas armadas. ${ }^{41}$ Entre las cárceles más utilizadas por las fuerzas armadas para el alojamiento de las personas a su disposición en esta instancia anterior al juicio ante los Tribunales Militares, encontramos pabellones de la Penitenciaria de Córdoba y la Penitenciaría Nacional. En estos lugares los detenidos esperaban la conformación de los Tribunales Militares, siendo trasladados las veces necesarias al sitio donde se encontraba conformado el Consejo de Guerra que llevaría adelante el juicio y juzgamiento.

Una vez que el tribunal militar expedía la condena, generalmente comenzaban una serie de traslados entre distintas unidades carcelarias situadas en la Provincia de Buenos Aires y en la región central del país. El primer y principal destino dentro de la provincia de Buenos Aires era la Cárcel Militar de Magdalena, como figura nombrada en los registros de la época. ${ }^{42}$ Varios ex presos Conintes hacen mención a estos traslados constantes, a esta dinámica de "pasearlos de cárcel en cárcel” (Damin, 2010). Durante este procedimiento, las personas que habían sido detenidas en grupo generalmente permanecían juntas.

Ahora bien, podemos marcar un último momento en el que los militares procedían al traslado de los condenados Conintes a instituciones carcelarias ubicadas en regiones muy alejadas a las residencias de los detenidos. ${ }^{43}$ Es así que finalmente los detenidos llegaban al destino carcelario en el que cumplirían la mayor parte de su condena. Estos destinos se caracterizaban por su ubicación geográfica remota, muy alejada del lugar de residencia de los detenidos, situados en provincias del Norte o Sur del país. De esta manera, los destinos finales a los cuales las fuerzas militares trasladaban a los presos Conintes eran las cárceles de Viedma, Rawson y Ushuaia al sur del país, y las cárceles de Resistencia y Coronda al norte. Los legisladores de la Comisión invirtieron gran parte de sus esfuerzos en investigar y recabar información sobre estos últimos destinos carcelarios, centrándose sobre todo en las cárceles de Ushuaia y Viedma. De esta manera también confirmaron que, sumado a la lejanía de estos destinos y el consecuente aislamiento que ello significaba, las condiciones materiales en las que vivían los presos Conintes eran deplorables. ${ }^{44}$

Como ya analizamos, existían zonas de ciertas unidades penitenciarias al mando de las fuerzas armadas. Aquí, el caso de Ushuaia nos permite también estudiar de cerca los acuerdos existentes entre la Dirección Nacional de Institutos Penales y las autoridades militares en lo referente a las "divisiones" de jurisdicción al interior de la cárcel. A los tres meses de la sanción pública del plan Conintes, y en la medida en que estos detenidos políticos comenzaron a ser condenados por los Consejos de Guerra, el gobierno se planteó el problema del lugar de reclusión y cumplimiento de condena de los mismos. 
Entre los destinos carcelarios elegidos, el Destacamento de Ushuaia de Institutos Penales, situado dentro de la Base Naval Ushuaia, constituyó uno de los destinos privilegiados. ${ }^{45}$ En el mes de junio de 1960 se firmó un acuerdo entre el representante de aquella Dirección en la cárcel de Ushuaia, Prefecto Raúl Ambros, y el Comandante de la Base Naval de Ushuaia, Capitán de Navío Rafael Palomeque, en el cual se establecieron las pautas bajo las cuales se permitiría y se regiría el alojamiento de "condenados por la Justicia Militar, por motivaciones terroristas y afines”. ${ }^{46}$ En primer lugar, la Base Naval se comprometía a alojar allí a 21 personas pertenecientes a la Dirección Nacional de Institutos Penales y a proveerlos de vivienda, alimentos y todo lo necesario para su estadía. Además dicho acuerdo establecía que se designaría un pabellón específicamente para los condenados por el Plan Conintes y que el orden interno estaría a cargo de Institutos Penales, quedando restringido el acceso al Penal a solo tres autoridades específicas de la Base Naval. De la misma manera, quedaba estipulado que las fuerzas armadas debían informar a las autoridades de la prisión "respecto de los cómputos de pena y la fecha de cumplimiento de las condenas de los alojados en el Penal, como así también las relativas a traslados". ${ }^{47}$ De esta manera, la cárcel clausurada por el peronismo y reabierta por la Revolución Libertadora para alojar a militantes peronistas, era nuevamente puesta en funcionamiento durante el gobierno de Frondizi con el fin de confinar allí a los presos condenados por "terroristas". ${ }^{48}$ De esta manera quedaban reglamentadas, al menos a grandes rasgos, las divisiones de tareas entre las autoridades militares y del Penal, y la administración del mismo. En este caso, las autoridades militares no tendrían control directo de los condenados, como sí se registra en las fuentes documentales para los casos de los pabellones de las Penitenciarías de Córdoba, Penitenciaría Nacional y cárcel de Magdalena.

El caso de la cárcel de Ushuaia constituye un ejemplo paradigmático de la aplicación del plan Conintes y del simbolismo de las cárceles para el gobierno en dicho contexto. En septiembre de 1960 varios diputados viajaron hasta aquel destino para entrevistarse con 42 presos que habían sido confinados allí para cumplir las condenas impuestas por las fuerzas armadas en el marco del plan Conintes. ${ }^{49}$ En vista del tiempo disponible y la cantidad de detenidos, decidieron realizar una entrevista general con la presencia de todos ellos en la que se habló sobre las denuncias que habían llegado a los legisladores de la Comisión por medio de familiares y abogados. En dicha entrevista se ratificaron las denuncias sobre traslados clandestinos a lugares no especificados, la aplicación de torturas con el objetivo de extraer confesiones falsas, y las malas condiciones a las que eran sometidos en el Penal de Ushuaia. Luego, cada preso Conintes escribió una carta dirigida a la Comisión donde expresaban por escrito sus denuncias y reclamos. Estas cartas, sumado a las condiciones inhumanas de reclusión que los diputados pudieron constatar con su visita, fueron el material documental utilizado por la Comisión para solicitar al Ministro de Educación y Justicia, el día 14 de septiembre de 1960, el inmediato traslado de los detenidos. El traslado fue autorizado por el Ministro, quien se excusó en que el mismo no se había realizado antes para no "interrumpir" el trabajo de la Comisión. Pocos días después, fue efectivizado. Sin embargo, las condiciones allí tampoco eran óptimas y en poco tiempo llegaron a la cámara nuevas denuncias sobre malas condiciones y apremios ilegales. Una vez que los detenidos estuvieron en Viedma, los diputados se entrevistaron allí con ellos de manera individual, continuando así su lucha por el traslado de los detenidos a la cárcel de Magdalena.

Ahora bien, luego de esta descripción a grandes rasgos acerca de la dinámica de detención desplegada durante la aplicación del Plan Conintes, queda reflexionar sobre el accionar represivo de las autoridades que lo llevaron a cabo. En este punto, como ya dijimos, los protagonistas de la represión al terrorismo fueron tanto las fuerzas armadas como la Policía Federal y provinciales, subordinadas a ella. En el caso de la Provincia de Buenos Aires, durante la vigencia del Plan Conintes dicha fuerza de seguridad fue dividida hacia su interior en dos conducciones distintas: la policía dedicada a las tareas ordinarias y la policía Conintes (Barreneche, 2012). A las acusaciones realizadas hacia la policía en los casos de detención de personas por orden del Poder Ejecutivo Nacional, se le sumaron con la implementación del Plan Conintes serias denuncias en relación a su accionar en la represión del terrorismo. Con esto queremos decir que, en la mayoría de las denuncias 
recogidas por los diputados sobre prácticas ilegales en la detención desarrolladas dentro del plan Conintes, se encontraban comprometidas autoridades policiales. En la mayoría de las denuncias sobre torturas durante lo que denominamos aquí circuitos de detención, los denunciantes señalan comisarías o lugares que no podían precisar a los que eran llevados desde dependencias policiales para ser allí torturados. Ante esta situación, los representantes de la Comisión solicitaban entrevistas con los comisarios y demás personal a cargo de las instituciones involucradas. Generalmente, dichas autoridades y oficiales negaban tener conocimiento de las personas que denunciaban apremios y traslados ilegales, pero de algunas entrevistas se desprenden datos importantes que hacen a la dinámica de relaciones entre autoridades militares y policiales.

Las denuncias a las que hacemos referencia se relacionan tanto con abusos de autoridad cometidos por miembros de la fuerza en los momentos de la detención, como con posteriores torturas a los detenidos en las Comisarías o dependencias policiales a las que muchas veces eran llevados como primer momento de la detención. En este sentido, al menos para el caso de la policía de la provincia de Buenos Aires, existían disposiciones de la Jefatura de la Provincia que ordenaban la colaboración de las dependencias policiales respecto de los detenidos Conintes llevados a las mismas por autoridades militares. Según el testimonio del entonces Comisario de la Seccional Primera de la ciudad de La Plata a la Comisión, tal colaboración se refería a "préstamo de personal, medios de movilidad, calabozos, siendo la conducción de los detenidos a la dependencia a su cargo uno de esos tipos de colaboración". ${ }^{50}$ Este testimonio y otros similares dan cuenta tanto de la participación de las policías provinciales en los circuitos de detención de los presos Conintes como de las formas en que las autoridades policiales quedaban sujetas a las disposiciones militares.

Siguiendo este hilo, también las autoridades militares fueron puestas en evidencia en las denuncias que ingresaban a la Comisión. Los diputados se quejaban enfáticamente del accionar represivo de las fuerzas armadas. A las investigaciones ya realizadas, podemos aportar que desde los primeros debates (en junio de 1960) en que se trató el accionar de la Comisión varias voces afirmaron contundentemente que dentro del marco del Plan Conintes las Fuerzas Armadas torturaban gente. ${ }^{51}$ Del mismo modo, los diputados manifestaban el exceso de dramatismo y abuso de poder desplegado en los procedimientos de detención de personas bajo el Plan Conintes, así como también el hecho de que ciertos efectivos militares solían someter a humillación a los detenidos. ${ }^{52}$ Fueron muchos los casos denunciados en los que se acusaba a dichas fuerzas de apremios ilegales y de prácticas de torturas para sacar información a los presos Conintes $\mathrm{u}$ obligarlos a declarar en contra de su voluntad. Existen testimonios de detenidos Conintes que relatan distintos tipos de torturas desplegados contra ellos antes de la realización de los Juicios Militares. En este punto, otras investigaciones ya han puesto de manifiesto la influencia de la doctrina francesa entre los militares argentinos de aquel momento, formados incluso por personal del ejército francés en la aplicación de dichos procedimientos. ${ }^{53}$ Esta situación fue denunciada en la Cámara de Diputados durante los debates sobre la actuación de la Comisión y las denuncias recibidas.

\section{REFLEXIONES FINALES}

A partir del análisis sobre los destinos carcelarios de los perseguidos políticos durante el gobierno de Frondizi se desprende que existió una política de gobierno que pensó y teorizó sobre la importancia de los lugares de confinamiento de la disidencia. Así, los institutos penales ubicados en la región "central" del país, o en ocasiones en provincias vecinas como La Pampa o destinos cercanos a las capitales de las provincias, son las opciones elegidas para los presos a disposición del Poder Ejecutivo. En contraste, los presos Conintes pasaron casi todos por instituciones penitenciarias en ubicaciones remotas, principalmente en la parte sur del país, pero también se utilizaron instituciones alejadas respecto de la provincia de Buenos Aires hacia el norte, como lo atestigua el caso de los presos Conintes en Resistencia. ${ }^{54}$ Siguiendo esta lógica, también observamos la campaña de la Comisión por "acercar" a los presos Conintes a sus lugares de residencia, así 
como también las acciones desplegadas por los grupos de abogados y familiares de la Provincia de Buenos Aires y Córdoba persiguiendo el mismo objetivo de devolver a los detenidos a unidades penitenciarias situadas en sus respectivas provincias. Las resistencias de las fuerzas armadas, el Ministro de Defensa y el Poder Ejecutivo a aprobar dichas concesiones o darles lugar solo cuando se convertían en tema central en los medios, pone de manifiesto una concepción del castigo relacionada con la ubicación geográfica y las condiciones de los condenados.

Indagando en casos específicos, la continuidad que otorga Frondizi al uso de la cárcel de Ushuaia como destino de los presos Conintes marcó también una estrecha relación en cuanto a las lógicas de tratamiento de la disidencia política. En este artículo profundizamos sobre el envío de presos Conintes allí, y no de los presos políticos que mantenía recluidos a disposición del Poder Ejecutivo. Los encarcelamientos en destinos remotos e inhóspitos parecerían haber jugado un rol esencial como formas de castigo a la militancia "terrorista". Esto queda demostrado también en una de las reuniones del presidente de la Nación con los jefes de las Fuerzas Armadas, realizada los primeros días de marzo de 1960, con el objetivo de llegar a un acuerdo en cuanto a la forma de aplicación de la ley marcial, que desembocó en la sanción del ya mencionado decreto 2639. Ya finalizando el encuentro entre el Presidente, el Ministro de Defensa y los Secretarios de las fuerzas armadas, el primero ordena "tomar previsiones para alojamiento en las Islas Observatorio y de los Estados". 55 Estos destinos son islas que se encuentran ubicadas en el extremo sureste de la provincia de Tierra del Fuego.

Nos encontramos entonces frente a un Estado que comenzó reprimiendo y encarcelando en los primeros años a la disidencia política -mayormente peronista-y que, más adelante, realizó una distinción explícita al interior de dicha oposición. Como ya mencionamos, por un lado continuaron las órdenes de detenciones a militantes políticos; por otro, se inauguró -bajo la forma de los decretos del 13 y 15 de marzo de 1960la orden de detención de ciertos militantes bajo la acusación de terrorismo. En este punto, sostenemos que nos encontramos ante dos trayectorias judiciales diferentes, que implican procesos, autoridades y lugares de detención distintos. La tradición referida al Plan Conintes, que da protagonismo a las fuerzas armadas en la represión política y juzgamiento de civiles durante un gobierno constitucional, constituye un fenómeno al menos novedoso en la historia argentina. La implementación de un sistema que implicaba el uso regular de métodos de tortura estandarizados -como la picana eléctrica y la estrategia de dejar horas enteras al detenido mirando la pared- y el confinamiento en lugares geográficos remotos donde las condiciones de detención deplorables eran denunciadas constantemente, nos llevan a reflexionar sobre la apertura en este período de una nueva estructuración de la represión política.

Por otro lado, sabemos a partir de otras investigaciones académicas y también por los documentos consultados que existieron para los casos de presos Conintes varias agrupaciones destinadas a denunciar las irregularidades e ilegalidades de las cuales los detenidos eran víctimas. Sin embargo, no consta en los registros consultados que haya sucedido lo mismo respecto de los detenidos a disposición del Poder Ejecutivo. Creemos que, en parte, esto se debió a que la situación de los últimos era quizá más difícil de determinar. Es decir, los propios procesos confusos de detención, donde muchas veces se tardaba semanas o meses en informar la situación legal o el paradero del detenido, el hecho de no conocer tampoco el tiempo que duraría el confinamiento, hicieron que la identificación de los presos por decreto del Ejecutivo no llegaran en ese contexto a identificarse como un conjunto con experiencias similares. Esta hipótesis puede ganar sentido también a través del accionar de la propia Comisión, que si bien comenzó denunciando casos de detenidos políticos y gremiales a disposición del Poder Ejecutivo, luego la mayoría de sus esfuerzos se centraron en las denuncias Conintes. Creemos aquí que la visibilidad o no en los medios de comunicación también puede haber sido un factor influyente en estos casos.

A su vez, podríamos pensar en posibles relaciones de este andamiaje de detenciones irregulares, traslados no declarados, aplicación de torturas, cumplimientos de condenas en condiciones deplorables, entre otras cuestiones descriptas, con el último terrorismo de Estado de la historia Argentina. Creemos que el Plan Conintes corresponde a una forma más oscura de disciplinamiento social, donde el hecho de que sea 
aplicado por un gobierno democrático no es un factor menor. En tal contexto, tuvieron que desarrollarse también estrategias legales que permitiesen la aplicación de tal plan represivo, tanto para detener a personas a disposición del Poder Ejecutivo como para implementar el Plan Conintes. Resta indagar y reflexionar aquí también sobre con cuántas de estas estrategias y andamiajes legales, aunque muchas veces cuestionados como hemos visto, se continuó en la década siguiente. Esta pesquisa ha querido ser una primera aproximación a dicha temática, planteando más interrogantes que respuestas y dejando abiertos varios frentes de investigación, algunos de los cuales la autora se encuentra profundizando para la presentación de futuros avances.

\section{REFERENCIAS}

Barreneche, O. (2012). Formas de violencia policial en la provincia de Buenos Aires a comienzos de la década de 1960. Anuario Del Instituto De Historia Argentina, 12, 251-272. Recuperado de http://www.anuarioiha.fahce.unlp.e du.ar/article/view/IHAn12d08.

Barreneche, O. (2016). Policias en el banquillo. La justicia penal frente a la violencia y corrupción policial bonaerense en la década de 1960. Ponencia presentada en Jornadas Crimen y Sociedad: diez años de estudios sobre Policía, Delito y Justicia en perspectiva histórica, Bariloche, Argentina.

Chiarini, S. y Portugheis, R. (Coords.) (2014). Plan Conintes. Represión politica y sindical. Ciudad Autónoma de Buenos Aires: Ministerio de Justicia y Derechos Humanos de la Nación. Secretaría de Derechos Humanos. Archivo Nacional de la Memoria.

Damin, N. (2010). Plan Conintes y resistencia peronista 1955-1963. Buenos Aires: Instituto Nacional Juan Domingo Perón.

Fayó, I. (2005). Plan Conintes: aproximaciones a la definición de un problema. Ponencia presentada en V Jornadas Nacionales de Filosofía y Ciencia Política, Mar del Plata, Argentina.

Fayó, I. (2007). La implementación del Plan CONINTES durante el gobierno Frondicista, entre noviembre de 1958 y marzo de 1960. Ponencia presentada en Jornadas de Jóvenes Investigadores en Ciencias Sociales de la Universidad Nacional de Mar del Plata, Mar del Plata, Argentina.

Franco, M. (2012). Rompecabezas para armar: la seguridad interior como política de estado en la historia Argentina reciente (1958-1976). Contemporánea, 3, 77-96. Recuperado de https://dialnet.unirioja.es/servlet/articulo?co $\operatorname{digo}=4224576$

Franco, M., \& Iglesias, M. (2015). El estado de excepción a escala comparada: Notas a partir de los casos argentino, chileno y uruguayo durante la década de 1950. Quinto sol, 19(1), 1-23. Recuperado de https://cerac.unlpam.ed u.ar/index.php/quintosol/article/view/964/1581.

Kohen, A. (1980). El Caso Ingalinella. 25 años después. Buenos Aires: Ediciones Centro de Estudios.

Lafiandra, F. (1955). Los panfletos. Su aporte a la Revolución Libertadora. Recopilación y comentario. Buenos Aires: Itinerarium.

Pla, A. J. (1974). Nuevos Fracasos Radicales: división y presidencias (1955-1966). En L. Romero y Otros (Ed.), El radicalismo (pp. 249-278), Buenos Aires: CEPE.

Plater, G. (1956). Una gran lección. Buenos Aires: Almafuerte.

Pontoriero, E. (2015). Estado de excepción y contrainsurgencia: el Plan CONINTES y la militarización de la seguridad interna en la Argentina (1958-1962). Contenciosa, 3(4), 1-17. Recuperado de http://www.contenciosa.org/Sit io/VerArticulo.aspx?i=40.

Pontoriero, E. D. (2017). Excepcionalidad jurídica y contrainsurgencia: claves para pensar la racionalidad militar en los inicios del terror de Estado en Argentina (1973-1976). Revista Páginas, 9(19), 53-74. Recuperado de http:/ /revistapaginas.unr.edu.ar/index.php/RevPaginas/article/view/250

Rodríguez Molas, R. (1985). Historia de la tortura y el orden represivo en la Argentina. Buenos Aires: Editorial Universitaria. 
Ruiz Moreno, I. (1994). La revolución del 55. Buenos Aires: Emecé.

Salvatore, R. D., y Aguirre, C. (2017). Revisitando El nacimiento de la penitenciaría en América Latina veinte años después. Revista de historia de las Prisiones, 4, 7-42. Recuperado de http://www.revistadeprisiones.com/revisita ndo-el-nacimiento-de-la-penitenciaria-en-america-latina-veinte-anos-despues/

Scocco, M. y Divinzenso, A. (2015). La creación y constitución del II Cuerpo de Ejército en los años sesenta. Jornadas Interdisciplinarias de Jóvenes Investigadores en Ciencias Sociales, IDAES-UNSAM.

Seveso, C. (2009). Escuelas de militancia: la experiencia de los presos políticos en Argentina, 1955-1972. $A$ Contracorriente: A Journal on Social History and Literature in Latin America, 6(3), 137-165.

Spinelli, M. E. (2013). De antiperonistas a peronistas revolucionarios. Las clases medias en el centro de la crisis politica argentina (1955-1973). Buenos Aires: Sudamericana.

Silva, J. (2012). Las cárceles de la "Nueva Argentina": Administración del castigo y catolicismo durante el peronismo clásico. Trabajos y comunicaciones, 38, 57-86. Recuperado de http://sedici.unlp.edu.ar/handle/10915/34882.

Summo, M., y Pontoriero, E. (2012). Pensar la "guerra revolucionaria": doctrina antisubversiva francesa y legislación de defensa en la Argentina (1958-1962). Cuadernos de Marte, 3, 285-306. Recuperado de http://publicaciones .sociales.uba.ar/index.php/cuadernosdemarte/article/view/690.

Szusterman, C. (1998). Frondizi: la política del desconcierto. Buenos Aires: Emecé Editores.

\section{Notas}

1 A lo largo del texto utilizamos el término subversión según aparece en el corpus documental del período analizado en este trabajo. Dejamos en claro que no refleja nuestra apreciación acerca del carácter de los detenidos, sino la de las fuentes.

$2 \mathrm{Al}$ referirnos a oposición, hacemos alusión a los individuos que, según las fuentes, aparecen catalogados por distintas instituciones del gobierno como peligrosos/amenazantes a los proyectos políticos del gobierno frondicista. Y, por estas razones, se ordenaba su detención. En general, la mayoría aparecen en las fuentes catalogados como peronistas o, en una proporción menor, comunistas.

3 Para mayor información sobre la utilización de las cárceles durante el peronismo en relación al encarcelamiento de la disidencia política, ver Silva, 2012.

4 J. Silva (2012) ha investigado sobre la reforma penitenciaria impulsada por el peronismo, la cual permitió mayor injerencia de las autoridades nacionales sobre los sistemas penitenciarios provinciales.

5 Para un detalle pormenorizado ver Franco \& Iglesias, 2015.

6 Ley 14.436, Anales de la Legislación Argentina, 1958. Esta iniciativa fue propuesta por el Ejecutivo y sancionada por unanimidad en ambas Cámaras.

7 Ley 14.436, Anales de la Legislación Argentina, 1958. Esta iniciativa fue propuesta por el Ejecutivo y sancionada por unanimidad en ambas Cámaras.

8 Ley 14.774, Estado de Sitio en todo el país. Anales de la Legislación Argentina, 1958.

9 La autora se encuentra en proceso de relevamiento de los decretos que pedían la detención de personas a disposición del Poder Ejecutivo. Aún no contamos con las cifras exactas, pero podemos afirmar que superan las 1500 personas y que existen numerosos pedidos de detención en los años 1958, 1959, 1960 y 1961.

10 Decreto Secreto 9880, 14/11/1958. Recuperado de: http://servicios.infoleg.gob.ar/infolegInternet/anexos/205000-2 09999/209052/norma.htm

11 Ley 14.774, Estado de Sitio en todo el país. Anales de la Legislación Argentina, 1958.

12 Ley 12.234, Organización de la Nación para Tiempos de Guerra., 1948, Tomo VIII, Segunda Edición, Buenos Aires: Editorial La Ley, p. 72-79.

13 Para ahondar en este tema, ver Pontoriero (2015).

14 Decreto 2639, 15 de marzo 1960. Anales de la Legislación Argentina, 1960.

15 Decreto 10.479, "Empleo de Fuerzas Militares para la protección de objetivos esenciales para la vida nacional. 06/11/61. Anales de la Legislación Argentina, 1961. Este decreto es uno de los ejemplos de las disposiciones legales posteriores al plan Conintes.

16 En el año 1957, con vistas a las elecciones de 1958, la Unión Cívica Radical se dividió en dos partidos: por un lado la UCRI (Intransigente) y por otro la UCRP (del Pueblo). Bajo la UCRI se aglutinaron los seguidores de Frondizi, quienes apoyaban tanto el acercamiento al peronismo proscripto como el distanciamiento del radicalismo respecto del gobierno de la Revolución Libertadora. En contraste, la UCRP estaba compuesta por el resto de los sectores radicales 
marcadamente antiperonistas, quienes mantenían estrechas relaciones con la Libertadora e incluso ocuparon cargos importantes durante tal gobierno de facto (Acuña, 1984; Pla, 1974; Spinelli, 2013). Durante el Frondicismo, la Cámara de Diputados estuvo compuesta por la mayoría oficialista (UCRI) y por el radicalismo del pueblo (Szusterman, 1998).

17 Diario de Sesiones de la Honorable Cámara de Diputados de la Nación (de aquí en más lo abreviaremos bajo la sigla DS), Reunión $24^{\circ}, 20$ de julio, 1960, p. 1330.

18 DS, Reunión 24\% 20 de julio, 1960, p. 1331.

19 DS, Reunión $24^{\circ}, 20$ de julio, 1960, p. 1338.

20 En el mes de mayo de 1960, al comienzo del período ordinario de Sesiones, la UCRP había propuesto la creación de una "Comisión Parlamentaria Permanente de defensa de los Derechos Humanos", con la finalidad de englobar las denuncias sobre los procesos de detención y apremios ilegales. La propuesta fue desestimada por el bloque de la mayoría.

21 Se hace referencia a la importancia de la opinión pública en la mayoría de los debates parlamentarios. Asimismo, para mayor información sobre la visibilidad pública a través de la prensa ver: Fayó, 2007.

22 La misma quedó constituida por 11 miembros de la Cámara: Presidente: Pablo Calabrese (UCRI); Secretario: Juan Carlos Manes (UCRI); Vocales: Porfirio Antonio Aquino (UCRI), Luis L. Boffi (UCRI), Horacio Osvaldo Domingorena (UCRI), Alfredo H. Escalada (UCRI), Nírido E. Santagada (UCRI), Carlos H. Perette (UCRP), Antulio F. Pozzio (UCRP), Ernesto E. Sammartino (UCRP), Adolfo Contte (h.) (LP) y Horacio Flavio Luelmo (UCRI).

23 Si bien este estudio se concentra en los detenidos políticos, vale aclarar que la Comisión Investigadora de Supuestos Apremios Ilegales también investigó casos de presos por delitos comunes. Mayormente, las denuncias eran sobre la aplicación de torturas por parte de la Policía Federal (DS, Reunión 5, 30/05/61, p. 506-521).

24 Existieron dos episodios sobresalientes. Uno corresponde al hallazgo de una picana eléctrica en la Brigada de Investigaciones de San Martín en abril de 1961 (Barreneche, 2016). El otro caso corresponde a las investigaciones de los diputados sobre los detenidos políticos y Conintes en la cárcel de Ushuaia a quienes, fruto de estas investigaciones, se les consiguió el traslado a Viedma y Rawson. Ambos tuvieron gran repercusión mediática, en parte alentada por los propios legisladores quienes se ocupaban de transmitir informes parciales de sus investigaciones a los medios de comunicación.

25 Caracterización del diputado Perette (UCRP) sobre la situación de presos Conintes y presos políticos, pronunciada durante la exposición de sus argumentos para volver a prorrogar el mandato de la Comisión Investigadora en la Cámara de Diputados. DS, Reunión 5º, 30 de Mayo, 1961, p. 515.

26 DS, 1958.

27 Decretos Presidenciales, Octubre 1958, Archivo General de la Nación.

28 Para un desarrollo exhaustivo sobre el tema ver: Franco \& Iglesias, 2015.

29 Para mayor información sobre legislación penitenciaria en este período ver Silva, 2012.

30 Dicha información queda de manifiesto en el texto de los decretos del Poder Ejecutivo. Ver: Decretos del Poder Ejecutivo Nacional (1958 a 1961), Archivo General de la Nación.

31 DS, 20 de Julio, 1960. Pág. 1335.

32 DS, 20 de Julio, 1960. Pág. 1330.

33 DS, 20 de Julio, 1960. El diputado Perette informa que posee una lista con 188 personas detenidas bajo las circunstancias mencionadas. En las sesiones siguientes, otros diputados harán alusión a nuevas listas y casos puntuales similares sobre detenidos a pedido del Poder Ejecutivo.

34 DS, 20 de Julio, 1960. Pág. 1335. Afirmaciones realizadas por el diputado del oficialismo Horacio Flavio Luelmo.

35 El desarrollo de esta temática está siendo abordado por la autora en otra investigación.

36 DS, 20 de Julio, 1960.

37 DS, 14 de Junio, 1961. Pág. 892 y 893.

38 Decreto n. ${ }^{\circ}$ 2639: Declaración de situación de emergencia grave; jurisdicción militar sobre los delitos de intimidación pública y terrorismo, Anales de la Legislación Argentina, Año 1960, Tomo XX, p. 367.

39 Intervención de Alfredo Palacios en el debate parlamentario del 18 de mayo de 1961 sobre la aplicación del Plan Conintes y las torturas a presos sociales y políticos. Cámara de Senadores (1961). En: Rodríguez Molas, 1985, pp. 203-203.

40 Para profundizar sobre el desempeño de las Fuerzas Armadas durante la aplicación del Plan Conintes, ver: Summo \& Pontoriero, 2012; Pontoriero, 2015; Scocco y Divinzenso, 2015.

41 Archivo Parlamentario, Honorable Cámara de Diputados de la Nación, Comisiones Especiales, Comisión Especial Investigadora de Supuestos Apremios Ilegales.

42 Archivo Parlamentario, Honorable Cámara de Diputados de la Nación, Comisiones Especiales, Comisión Especial Investigadora de Supuestos Apremios Ilegales.

43 "Denuncias sobre apremios ilegales - Junta provincial Liga Argentina derechos Hombre - Mendoza" y "Comunicaciones de Fliares de detenidos Córdoba”, (además de causas particulares que no se nombran aquí sus encabezados por cuestiones de protección de identidad), Archivo Parlamentario, Honorable Cámara de Diputados de la Nación, Comisiones Especiales, Comisión Especial Investigadora de Supuestos Apremios Ilegales. 
44 Denuncia sobre apremios ilegales - Detenidos en el Penal de Ushuaia, Archivo Parlamentario, Honorable Cámara de Diputados de la Nación, Comisiones Especiales, Comisión Especial Investigadora de Supuestos Apremios Ilegales.

$45 \mathrm{La}$ autora se encuentra profundizando en esta línea de investigación acerca de la relación entre las autoridades de los Institutos Penales y las fuerzas armadas en lo referente al alojamiento y tratamiento de los presos Conintes.

46 Archivo Parlamentario, Honorable Cámara de Diputados de la Nación, Comisiones Especiales, Comisión Especial Investigadora de Supuestos Apremios Ilegales.

47 Ídem.

48 Seveso (2009) confirma también la reapertura del Penal para el alojamiento de presos Conintes, focalizándose en las experiencias personales experimentadas por los mismos.

49 Existen 42 legajos particulares además del legajo general titulado Denuncia sobre apremios ilegales - Detenidos en el Penal de Ushuaia, Archivo Parlamentario, Honorable Cámara de Diputados de la Nación, Comisiones Especiales, Comisión Especial Investigadora de Supuestos Apremios Ilegales.

50 Denuncia sobre apremios ilegales (se omite el nombre del detenido), Archivo Archivo Parlamentario, Honorable Cámara de Diputados de la Nación, Comisiones Especiales, Comisión Especial Investigadora de Supuestos Apremios Ilegales.

51 DS, 20 de Julio, 1960. Pág. 1334.

52 Ibíd. El diputado de la UCRP Rodríguez Araya, quien había evidenciado también las relaciones de las Fuerzas Armadas argentinas con los militares franceses, denunciaba la forma en que los militares irrumpían en las casas a detener a acusados Conintes describiéndolos como "pistoleros del Far West".

53 Idea desarrollada en Chiarini y Portugheis, 2014.

54 Según testimonios de ex presos Conintes (En: Damin, 2010).

55 Fondo Centro de Estudios Nacionales (Fondo CEN), Archivos y Colecciones Particulares, Biblioteca Nacional de la República Argentina, Síntesis de lo expuesto en la reunión efectuada en el despacho del Exmo. Señor Presidente de la Nación el día 14 de Marzo de 1960. 